\title{
Epidemiological Status of Bacterial Meningitis Disease Following the Introduction of the Meningococcal A Conjugate Vaccine in the African Meningitis Belt
}

\author{
Andre Arsene Bita Fouda \\ Family Health Reproductive, Immunization Vaccine Development, World Health Organization, Brazzaville, Congo \\ Email address: \\ bitaandre@yahoo.fr

\section{To cite this article:} \\ Andre Arsene Bita Fouda. Epidemiological Status of Bacterial Meningitis Disease Following the Introduction of the Meningococcal A \\ Conjugate Vaccine in the African Meningitis Belt. International Journal of Immunology. Vol. 7, No. 1, 2019, pp. 12-22. \\ doi: $10.11648 /$ j.iji.20190701.13
}

Received: May 16, 2019; Accepted: June 25, 2019; Published: July 16, 2019

\begin{abstract}
Bacterial meningitis disease is a burden in the African meningitis belt. Before 2010, Neisseria meningitidis serogroup A ( $N$. meningitidis A) was the predominant pathogen causing about 90 percent of meningitis epidemics in Africa. The meningococcal A conjugate vaccine (MACV) protecting against N. meningitidis A was introduced since 2010. The purpose of this quantitative study was to determine the magnitude and fatality of meningitis bacterial disease in Africa following the introduction of MACV from 2010 and 2017. An interrupted time series design and nonprobability sampling were used. Secondary data issued of meningitis enhanced surveillance were retrieved from World Health Organization database. The binomial negative regression and Pearson's Chi-Square tests were used. The study found that after the MACV introduction there was a 39\% decline of incidence rate of meningitis suspected cases (IRR $0.61,95 \%$ CI $0.48-0.79, p<.001$ ) and $99 \%$ decline of the risk of $N$. meningitidis A (RR 0.01, 95\% CI 0.08-0.013). There was a difference in the meningitis CFR before and after MACV introduction in 21 out of the 26 countries of African meningitis belt. After the introduction of MACV, there was a $46 \%$ decline in risk to report high $C F R(>10 \%)$ after the MACV immunization (RR 0.547, 95\% CI 0.40 - 0.74). There was a $49 \%$ decline of fatal meningitis (IRR 0.51, 95\% CI $0.41-0.68, p<.001$ ). After 2010, N. meningitidis A declined and $S$. Pneumoniae, N. meningitidis W135, N. meningitidis C, N. meningitidis X, and Hib became predominant. Between 2010 and $2017 N$. meningitidis all serogroups concerned remained higher the other pathogens 15,885 (62.06\%) Vs 25,596. The study showed that following the MACV introduction despite the dramatic reduction of $N$. meningitidis A, meningococcal meningitis bacterial disease remains a major public health problem.
\end{abstract}

Keywords: Meningitis, Neisseria meningitidis, Meningococcal a Conjugate Vaccine, African Meningitis Belt, Crude Fatality Rate

\section{Introduction}

Meningitis remains a burden for the 26 countries of the African meningitis belt, stretching from Senegal in the west to Ethiopia in the east $[1,2]$. The bacterial is a serious infection of the meninges, thin fibrous tissue that covers the brain and spinal cord. It can cause severe brain damage and is fatal in $50 \%$ of cases if left untreated. The common risk factors are age between 1 to 29 years old, community setting, environment, and travel. The findings showed that meningococcal meningitis has the greatest incidence with large epidemics in Africa in the dry season. N. meningitidis is transmitted from person-to-person through droplets of respiratory or throat secretions from carriers. Ten percent to $20 \%$ of the population carries $N$. meningitidis in their throat at any given time [3].

By far the highest incidence of meningococcal disease occurs in the meningitis belt of sub-Saharan Africa. During epidemics, the incidence can approach 1,000 per 100,000 , or $1 \%$ of the population. Of the 12 serogroups of $N$. meningitidis identified, four serogroups, A, B, C, and W135, are recognized to be the main causes of epidemics. Meningococcal meningitis cases occur throughout the world. Before the introduction of MACV in 2010, N. meningitidis A 
accounted for an estimated 90 percent of all cases in the African meningitis belt, with epidemics occurring at intervals of 5-10 years. This study also aimed to show that bacterial meningitis remains a burden in the African meningitis belt despite the introduction of MACV $[4,5,6]$. MACV provides herd and individual protection. Between 2010 and 2017, 21 countries have introduced MACV with more than 280 million people vaccinated aged 1 to 29 years through vaccination mass campaigns $[1,7,8]$.

The reduction of the incidence of bacterial meningitis cases, epidemics and deaths following the introduction of MACV into meningtis belt was demonstrated [1, 9-24]. Novak et al. showed $71 \%$ decline in risk of meningitis (suspected cases) in Burkina Faso 1 year after the introduction of MACV [11]. Daugla et al. (2013) found a $94 \%$ reduction in the incidence of meningitis in a vaccinated population within 4-6 months after MACV mass vaccination campaign in Chad [12]. A study conducted by Trotter et al. found in nine countries (Benin, Burkina Faso, Chad, Côte d'Ivoire, Ghana, Mali, Niger, Nigeria, Togo) a $58 \%$ decline in incidence of meningitis (suspected cases) and 60\% decline in epidemics risk of a district reaching the epidemic threshold [13]. Findings also showed the signifcant reduction of $\mathrm{NmA}$ incidence and carriage following the immunization with MACV [3, 12, 14]. Following the introduction of MACV authors found the change of bacterial meningitis profile with the predominance of $N$. meningitidis $C, N$. meningitidis $W, N$. meningitidis $X, S$. pneumoniae, and $H b i$ [9, 18, 21-28].

This study considered 21 out of 26 of meningitis belt countries. Meningitis surveillance has been enhanced since 2002 in the African meningitis belt countries. In preparation for the introduction of MACV an enhanced meningitis surveillance network was established by WHO since 2002 . Meningitis enhanced surveillance aims to assess the effects of the introduction of new vaccines, to detect and confirm epidemics and launch appropriate response strategies, to assess case burden and incidence trends, to monitor the antibiotic resistance profile of $N$. meningitidis, including $N$. meningitidis $A$ or other pathogens, and to monitor the circulation, distribution, and evolution of $\mathrm{N}$. meningitidis serogroups and other pathogens. It helps not only to detect epidemics earlier but also to control the elimination of disease [29].

The purpose of this quantitative study was to determine the magnitude and fatality of meningitis bacterial disease in Africa following the introduction of MACV from 2010 and
2017. The potential positive social change is the reinforcement of public health policies, especially on surveillance and immunization, to achieve the elimination of vaccine-preventable diseases. The high coverage of vaccines against bacterial meningitis and the high quality of meningitis enhanced surveillance might be two relevant factors in achieving the elimination of bacterial meningitis. In addressing and emphasizing these factors; sought in this study to create a positive social change with the strengthening of immunization and surveillance policies.

\section{Methods}

\subsection{Study and Research Design}

The study was quasi-experimental, retrospective, and quantitative. The research design was an interrupted time series. Secondary data retrieved from WHO IST WA database concerned meningitis suspected cases, CFR, deaths, N. meningitidis A confirmed cases before and after 2010. Secondary data from meningitis enhanced surveillance and $\mathrm{MACV}^{\circledR}$ coverage concerned the period from 2004 to 2017. No time and resource constraints were found.

\subsection{Population}

The population of this study was characterized by people living in 1,713 out of 3,817 health districts at highest risk for meningitis in 21 countries of the African meningitis belt. Health districts at highest risk for meningitis were selected to introduce MACV ${ }^{\circledR}$. The selection was made through risk assessment using the district prioritization tool developed by WHO [30]. The 21 countries that were participants of this study were Mali, Burkina Faso, Cameroon, Central Africa Republic, Chad, Benin, Cote d'Ivoire, Togo, Mauritania, Niger, Nigeria, Ghana, Gambia, Guinea, Guinea Bissau, Ethiopia, Sudan, South Sudan, Senegal, and Uganda [1]. The total estimated population was 407,958,506 persons. People who were vaccinated with MACV were aged 1-29 years old because they were the highest risk of meningitis infection caused by $N$. meningitidis A. The age group 1-29 years old represented almost $70 \%$ of the total population. The estimated target population for MACV vaccination was $285,570,957$ people. The table 1 shows that between 2010 and 2017, 286,995,073 were immunized with MACV, thus there was $100 \%$ administrative coverage in the 21 countries of the study.

Table 1. People Vaccinated with MACV 2010-17.

\begin{tabular}{|c|c|c|c|c|c|c|}
\hline Countries & $\begin{array}{l}\text { Total population } \\
2017 \text { at meningitis } \\
\text { risk }\end{array}$ & $\begin{array}{l}\text { Health districts at high risk } \\
\text { covered By MenAfriVac } \\
\text { vaccination campaign }\end{array}$ & $\begin{array}{l}\text { Years of } \\
\text { introduction }\end{array}$ & $\begin{array}{l}\text { The target population } \\
\text { for MenAfriVac } \\
\text { vaccination campaigns }\end{array}$ & $\begin{array}{l}\text { Persons } \\
\text { vaccinated }\end{array}$ & $\begin{array}{l}\text { Administrative } \\
\text { coverage }\end{array}$ \\
\hline Benin & 3708077 & 33 & 2013 & 2595654 & 2718459 & $105 \%$ \\
\hline Burkina Faso & 21557784 & 63 & 2010,2016 & 15090449 & 15295276 & $101.35 \%$ \\
\hline Cameroon & 8751220 & 70 & 2011-12 & 6125854 & 6510729 & $112.80 \%$ \\
\hline Central African Republic & 5226069 & 30 & 2017 & 3658248 & 3220358 & $88.24 \%$ \\
\hline Chad & 13177019 & 99 & 2011-12 & 9223913 & 8732151 & 95 \\
\hline $\begin{array}{l}\text { Democratic Republic of } \\
\text { Congo }\end{array}$ & 26008263 & 149 & 2016 & 18205784 & 18058535 & $99.20 \%$ \\
\hline
\end{tabular}




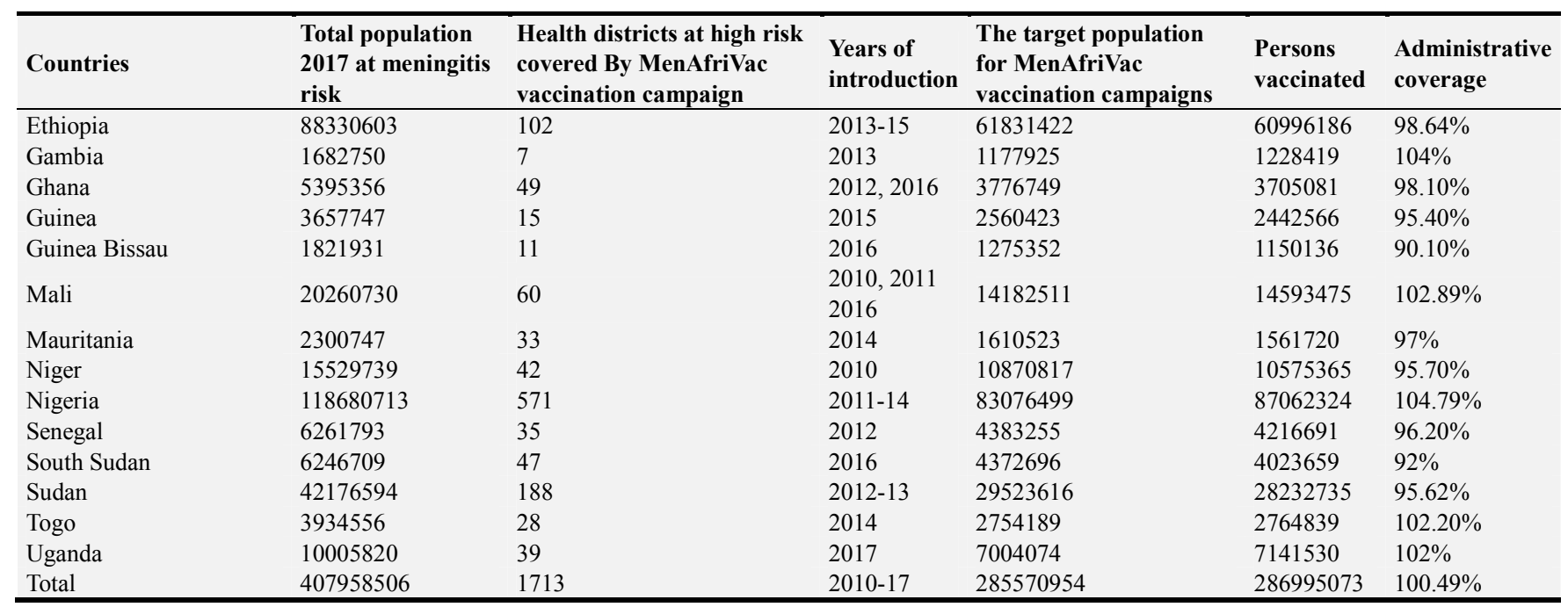

Note. Source WHO.

\subsection{Data Collection and Instrumentation}

The secondary data of this study were retrieved between February 10 and February 28, 2018, from WHO ISTWA databases and WHO websites and there were accurate. These data concerned meningitis surveillance between 2004 and 2017 and MACV introduction from 2010 to 2017. The secondary data from meningitis surveillance concerned especially meningitis suspected cases that fit the case definition, CFR, results of CSF samples tested in laboratories, and the meningitis epidemics due to $N$. meningitidis A reported by health districts using meningitis epidemic threshold. Concerning the MACV introduction, information gathered mainly concerned vaccination coverage. The data retrieved were aggregated and sent by countries on a regular basis. Data were sent on a weekly basis concerning meningitis surveillance, and monthly regarding MACV immunization activities. The data collected were prior treated, consolidated, harmonized, and validated at the country level before sending to WHO ISTWA. The dataset was created for this study so-called MenA_dataset. They were no discrepancies in data collection. Almost $2.5 \%$ of data were missing because few countries didn't share the data with WHO IST WA. The dependent variables selected were the occurrence of $N$. meningitidis A, laboratory-confirmed or not, meningitis suspected cases, CFR, deaths, and occurrence of meningitis epidemics due to $N$. meningitidis A as reported by health districts. The independent variable was MACV vaccination status of people living in health districts (vaccinated after the introduction of MACV; vaccinated with any other polysaccharide vaccine that includes antigen $A$; unvaccinated before the introduction of MACV). The distribution was a Poisson distribution, where the mean and variance differ from one another. In this study, observations were independent variables. The statistical assumptions for Pearson's Chi-Square were met because the observations for the two-way contingency table analysis were independent of each other, and all the expected occurrences of the crosstab were greater than five. The measuring instrument used in this study was meningitis enhanced surveillance. Enhanced surveillance can be used to evaluate the effects of the introduction of a new vaccine such as MACV [29].

\subsection{Data Analysis and Statistical Tests}

To find the difference of meningitis suspected cased before and after the introduction of MACV, incidence rate ratio (IRR) of meningitis suspected cases in vaccinated and unvaccinated populations were estimated using a negative binomial regression model. To find the difference of CFR of meningitis before and after the introduction of MACV, the Pearson's chi-square was used to determine whether or not they were the difference between CFR ( $>=10 \%$ or $<10 \%$ ). Additional IRR of deaths (fatal meningitis) was calculated using negative binomial regression. Descriptive and inferential statistics were conducted in this study using SPSS 21 version and Microsoft Excel 2013. Before conducting inferential statistics, cleaning data was done for all research questions. A codebook created contain variable names, variable labels, value labels, and a list of any changes.

\section{Results}

\subsection{Incidence of Bacterial Meningitis Suspected Cases}

The figure 1 shows a decline of meningitis suspected cases after 2010 in the 21 countries selected for the study out of the 26 of the African meningitis belt. Meningitis suspected cases remained high and therefore a public health problem after 2010. After 2010, the highest number of meningitis suspected cases reported was 29,335 in 2012 and ranged between was 18,938 and 29,335 . 


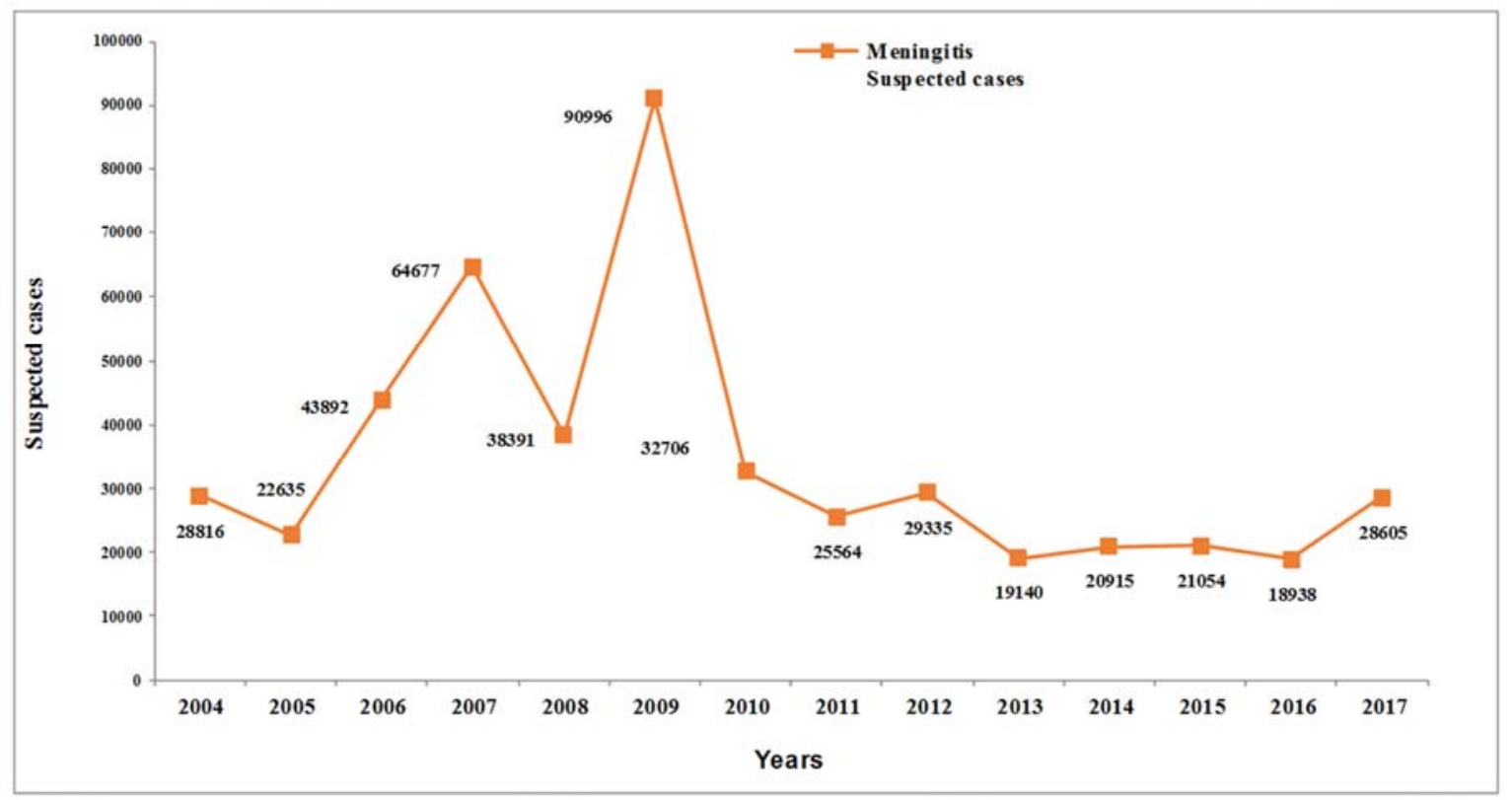

Figure 1. Meningitis suspected cases 2004-2017.

The table 2 shows that after the introduction of the MACV®, there was a $39 \%$ decline of incidence rate of meningitis suspected cases (IRR 0.61, 95\% CI $0.48-0.79$, p $<.001)$, with heterogeneity observed by country. The null hypothesis was rejected because it was less than .05. Therefore, there is a difference in incidence rate of the suspected cases of meningitis disease before and after MACV introduction in 21 out of the 26 countries of African meningitis belt between 2010 and 2017. The difference of incidence rate of the meningitis suspected cases was significant $(p<.05)$ in Burkina Faso, Nigeria, South Sudan, and Sudan.

Table 2. Incidence Rate Ratio for Meningitis Suspected Cases 2004-2017.

\begin{tabular}{|c|c|c|c|}
\hline & IRR & $95 \%$ CI & $\mathbf{p}$ \\
\hline All & 0.61 & $0.48-0.79$ & .000 \\
\hline Benin & 1.78 & $0.60-5.32$ & 0.301 \\
\hline Cameroon & 1.99 & $0.69-5.69$ & 0.197 \\
\hline Central African republic & 2.88 & $0.38-22.06$ & 0.308 \\
\hline Chad & 0.19 & $0.02-1.45$ & 0.11 \\
\hline Ethiopia & 11.17 & $3.50-35.68$ & 0.014 \\
\hline Gambia & 0.87 & $0.29-2.64$ & 0.881 \\
\hline Ghana & 1.45 & $0.50-4.20$ & 0.488 \\
\hline Guinea & 0.61 & $0.17-2.26$ & 0.461 \\
\hline Guinea- Bissau & 7.31 & $1.59-33.6$ & 0.011 \\
\hline Ivory coast & 0.5 & $0.16-1.60$ & 0.244 \\
\hline Mauritania & 0.35 & $0.09-1.33$ & 0.125 \\
\hline Niger & 0.49 & $0.17-1.42$ & 0.188 \\
\hline Nigeria & 0.25 & $0.09-0.70$ & .000 \\
\hline Senegal & 3.28 & $1.14-9.49$ & 0.028 \\
\hline South Sudan & 0.02 & $0.005-0.10$ & .000 \\
\hline Sudan & 0.11 & $0.04-0.35$ & 0.033 \\
\hline Togo & 1.75 & $0.55-5.60$ & 0.343 \\
\hline Uganda & 0.25 & $0.03-1.97$ & 0.187 \\
\hline
\end{tabular}

Note. $\mathrm{IRR}=$ Incidence Rate Ratio. $\mathrm{CI}=$ Confident Interval. NA $=$ Not Applicable. $\mathrm{p}=\mathrm{p}$-value.

\subsection{Deaths and Crude Fatality Rate}

The figure 2 shows that between 2014 and 2017, the highest number of deaths caused by meningitis disease was 5,507 reported in 2009. The lowest number of deaths was 1,418 reported in 2016 . The number of meningitis deaths was 
higher before 2010. After 2010 CFR and deaths. The CFR was higher before 2010; most were over $10 \%$. The highest
CFR was $14 \%$ reported in 2004, and the lowest CFR was $6 \%$ reported in 2017 (see figure 2).

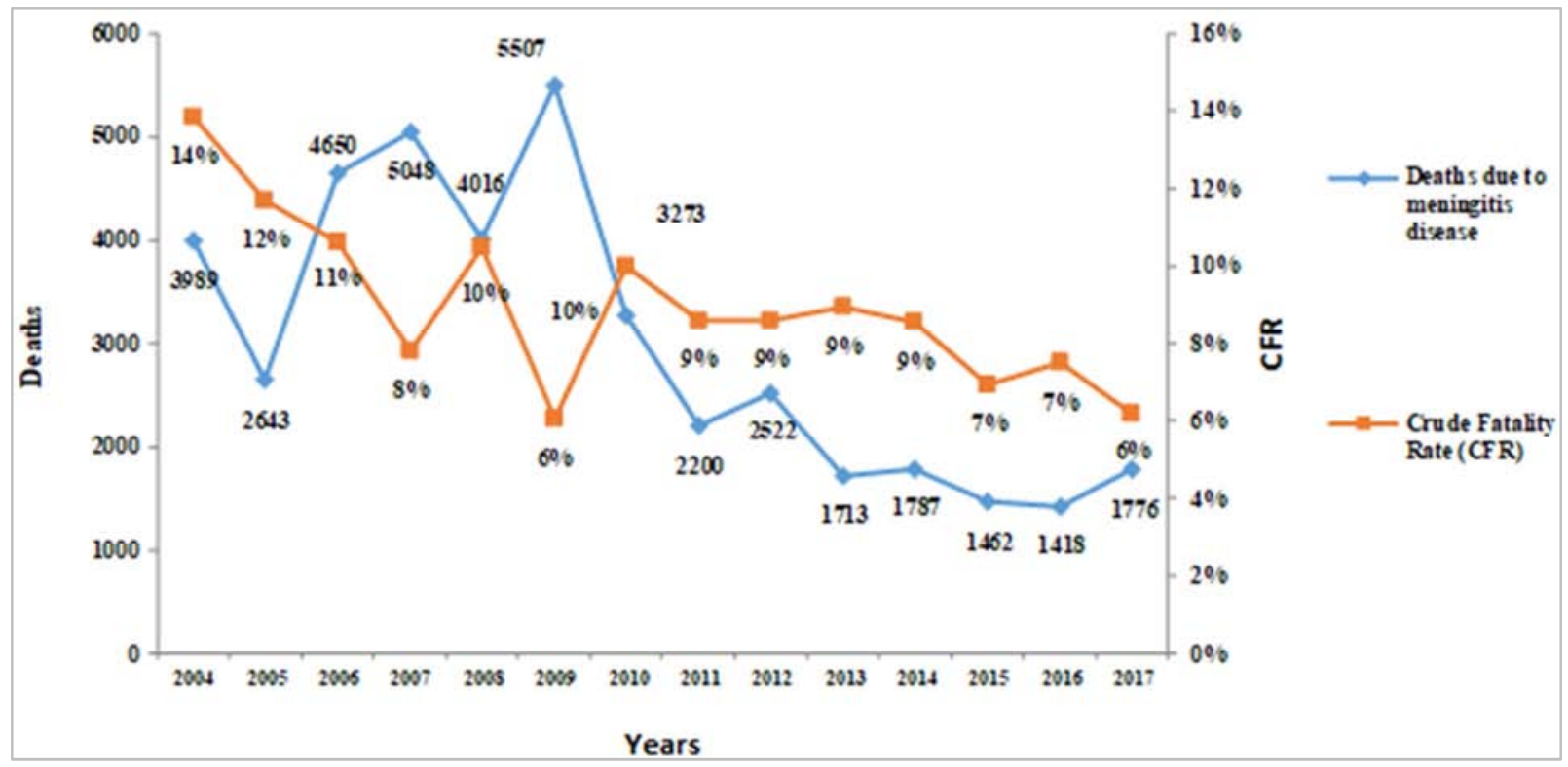

Figure 2. Incidence of meningitis deaths and crude fatality rate 2004-2017.

The table 3 shows that $X^{2}(1)=14.18, p=.000$. The null hypothesis was rejected because $\mathrm{p}$ was less than 05 . Therefore, there was a difference in the meningitis CFR before and after MACV introduction in 21 out of the 26 countries of African meningitis belt. The table 4 shows that there was $46 \%$ decline of risk to report high $C F R(>=10 \%)$ after the MACV immunization (RR 0.547 , 95\% CI $0.40-$ 0.74). Table 5 shows that after the introduction of the MACV vaccine, there was a $49 \%$ decline of meningitis deaths (IRR $0.51,95 \%$ CI $0.40-0.66, \mathrm{p}<.001$ ), with heterogeneity observed by country. There was a difference in fatal meningitis before and after MACV introduction in 21 out of the 26 countries of African meningitis belt. The difference in the fatal meningitis was significant $(p<.05)$ in Ivory Coast, Mali, Mauritania, Nigeria, South Sudan, and Sudan.

Table 3. Chi-Square Tests for CFR and MACV Introduction.

\begin{tabular}{llllll}
\hline & Value & df & Asymp. Sig. (2-sided) & Exact Sig. (2-sided) & Exact Sig. (1-sided) \\
\hline Pearson Chi-Square & $15.792^{\mathrm{a}}$ & 1 & .000 & & \\
Continuity Correction & 14.826 & 1 & .000 & & .000 \\
Likelihood Ratio & 15.944 & 1 & .000 & .000 & .000 \\
Fisher's Exact Tests & & & & & \\
N of Valid Cases & 274 & & & & \\
\hline
\end{tabular}

a. 0 cells $(0.0 \%)$ have expected count less than 5 . The minimum expected count is 39.12 .

b. Computed only for a $2 \times 2$ table.

Table 4. Risk Estimate of CFR and MACV Introduction.

\begin{tabular}{llll}
\hline & \multirow{2}{*}{ Value } & \multicolumn{2}{c}{ 95\% Confidence Interval } \\
\cline { 3 - 4 } & & Lower & \multicolumn{2}{l}{ Upper } & 4.487 \\
\hline Odds Ratio for Factor (After MACV introduction / Before MACV introduction) & 2.722 & 1.652 & 1.827 \\
For cohort $C F R=$ No & 1.489 & 1.213 & .745 \\
For cohort $C F R=$ Yes & .547 & .401 & \\
N of Valid Cases & 274 & & \\
\hline
\end{tabular}

Table 5. Incidence Risk Ratio of Meningitis Deaths 2004-2017.

\begin{tabular}{llll}
\hline & IRR & $\mathbf{9 5 \% C I}$ & p \\
\hline All & 0.51 & $0.40-0.66$ & .000 \\
Benin & 1.13 & $0.38-3.38$ & 0.301 \\
Burkina Faso & 0.38 & $0.13-1.10$ & 0.073 \\
Cameroon & 1 & $0.34-2.87$ & 0.99 \\
Central African republic & 1.72 & $0.22-13.27$ & 0.308 \\
Chad & 0.16 & $0.02-1.27$ & 0.11 \\
Democratic republic of Congo & 0.27 & $0.06-1.19$ & 0.157 \\
\hline
\end{tabular}




\begin{tabular}{llll}
\hline & IRR & $\mathbf{9 5 \% C I}$ & p \\
\hline Ethiopia & 0.74 & $0.23-2.42$ & 0.620 \\
Gambia & 2.48 & $0.69-8.80$ & 0.162 \\
Ghana & 0.91 & $0.31-2.64$ & 0.488 \\
Guinea & 0.39 & $0.10-1.49$ & 0.461 \\
Guinea-Bissau & NA & & 0.032 \\
Ivory coast & 0.27 & $0.08-0.89$ & 0.026 \\
Mali & 0.29 & $0.10-0.86$ & .000 \\
Mauritania & 0 & $0.00-0.00$ & 0.188 \\
Niger & 0.61 & $0.21-1.77$ & 0.009 \\
Nigeria & 0.24 & $0.08-0.69$ & 0.400 \\
Senegal & 1.61 & $0.53-4.92$ & .000 \\
South Sudan & 0.012 & $0.002-0.08$ & .000 \\
Sudan & 0.08 & $0.02-0.26$ & 0.343 \\
Togo & 0.95 & $0.29-3.06$ & 0.638 \\
Uganda & 0.59 & $0.07-5.25$ & \\
\hline
\end{tabular}

Note. IRR $=$ Incidence Rate Ratio. $\mathrm{CI}=$ Confident Interval. $\mathrm{NA}=$ Not Applicable. $\mathrm{p}=\mathrm{p}$-value.

Profile of bacterial meningitis pathogen

The table 6 shows the decline of $N$. meningitidis A after 2010 and the predominance of S. Pneumoniae, N. meningitidis $\mathrm{W} 135, N$. meningitidis $\mathrm{C}, N$. meningitidis X, and Hib. N. meningitidis confirmed remain predominant 15,885 (62.06\%) out of 25,596 meningitis pathogens confirmed between 2010 and 2017.

Table 6. Meningitis Pathogens Profile.

\begin{tabular}{|c|c|c|c|c|c|c|}
\hline $\begin{array}{l}\text { Countries } \\
\text { Years } \\
\end{array}$ & N.meningitidis A & N. meningitidis B & N. meningitidis W135 & N. meningitidis $\mathbf{C}$ & N. meningitidis $\mathbf{X}$ & N. meningitidis $Y$ \\
\hline 2004 & 682 & 0 & 125 & 0 & 0 & 0 \\
\hline 2005 & 170 & 0 & 33 & 0 & 0 & 0 \\
\hline 2006 & 954 & 0 & 34 & 0 & 0 & 0 \\
\hline 2007 & 779 & 0 & 62 & 0 & 0 & 0 \\
\hline 2008 & 1102 & 0 & 7 & 0 & 0 & 0 \\
\hline 2009 & 2066 & 0 & 167 & 0 & 0 & 0 \\
\hline 2010 & 484 & 0 & 727 & 4 & 55 & 0 \\
\hline 2011 & 214 & 0 & 487 & 0 & 128 & 0 \\
\hline 2012 & 88 & 1 & 1009 & 4 & 138 & 1 \\
\hline 2013 & 23 & 2 & 237 & 10 & 15 & 0 \\
\hline 2014 & 6 & 2 & 286 & 48 & 11 & 1 \\
\hline 2015 & 80 & 2 & 545 & 1224 & 20 & 0 \\
\hline 2016 & 9 & 1 & 719 & 375 & 68 & 6 \\
\hline 2017 & 2 & 0 & 263 & 891 & 333 & 2 \\
\hline Total & 6659 & 8 & 4701 & 2556 & 768 & 10 \\
\hline
\end{tabular}

Table 6. Continued.

\begin{tabular}{|c|c|c|c|c|c|}
\hline Countries & \multirow{2}{*}{ Other $N$. menin gitidis } & \multirow{2}{*}{ S.pneumoniae } & \multirow{2}{*}{ Hemophilus influenza b } & \multirow{2}{*}{ Other Pathogens } & \multirow{2}{*}{ Total } \\
\hline Years & & & & & \\
\hline 2004 & 48 & 447 & 104 & 0 & 1406 \\
\hline 2005 & 53 & 323 & 125 & 61 & 765 \\
\hline 2006 & 441 & 234 & 95 & 60 & 1818 \\
\hline 2007 & 9 & 297 & 74 & 50 & 1271 \\
\hline 2008 & 65 & 243 & 48 & 39 & 1504 \\
\hline 2009 & 29 & 355 & 37 & 74 & 2728 \\
\hline 2010 & 14 & 351 & 47 & 25 & 1707 \\
\hline 2011 & 4 & 748 & 40 & 27 & 1648 \\
\hline 2012 & 31 & 539 & 45 & 25 & 1881 \\
\hline 2013 & 57 & 466 & 38 & 55 & 903 \\
\hline 2014 & 34 & 656 & 50 & 76 & 1170 \\
\hline 2015 & 62 & 734 & 40 & 243 & 2950 \\
\hline 2016 & 296 & 1062 & 87 & 416 & 3039 \\
\hline 2017 & 40 & 809 & 136 & 330 & 2806 \\
\hline Total & 1183 & 7264 & 966 & 1481 & 25596 \\
\hline
\end{tabular}




\section{Discussion}

\subsection{Meningitis Suspected Cases Reported Before and After MACV Introduction}

The study found $39 \%$ decline of incidence rate of meningitis suspected cases (IRR $0.61,95 \%$ CI $0.48-0.79, p$ $<.001)$ after the introduction of MACV ${ }^{\circledR}$, with heterogeneity observed by country. These results confirm the same trend of reduction of meningitis suspected cases found in the literature review [1, 11-13, 15-16, 24]. However, Trotter et al. found a $57 \%$ decline of meningitis suspected cases in nine countries (Benin, Burkina Faso, Chad, Ivory Coast, Ghana, Mali, Niger, Nigeria, and Togo) five years after introduction of MACV (IRR 0.43, 95\% CI 0.41-0.45, $p<.001$ ) [13]. In Burkina Faso in 2012, Novak et al. found $71 \%$ decline of meningitis suspected cases one year after the introduction of MACV (hazard ratio $0.29,95 \%$ CI $0.28-0.30$ ) and Trotter et al. found a decline of $70 \% 5$ years after the introduction of MACV (IRR 0.30, 95\%CI 0.29-0.31) [11, 13]. This study found a $77 \%$ decline 7 year after the introduction of MACV in Burkina Faso (IRR 0.33, 95\% CI 0.12-0.96, $p<.001$ ). Conversely, Trotter et al. and Daugla et al. found respectively 91\% (IRR 0.086, 95\%CI 0.077-0.097) and 94\% $(p<0.0001)$ of reduction of meningitis deaths in Chad [12-13]. This study also found that the decrease of meningitis deaths before and after the introduction of MACV was significant (IRR 0.19, 95\% CI 0.02-1.45).

\subsection{Meningitis CFR and Deaths Reported Before and After MACV Introduction}

The study found a $46 \%$ decline of risk to report high $C F R$ $(>=10 \%$ ) after the MACV immunization (RR 0.547, 95\% CI $0.40-0.74$ ) and $49 \%$ decline of fatal meningitis (IRR $0.51,95 \%$ CI $0.41-0.68, p<.001$ ), with heterogeneity observed by country. The results confirm the findings of the literature $[1,11,15]$. The decline of high CFR can be explained by the modification of treatment protocol that was included since 2014 ceftriaxone. Diallo et al. found between 2011 and 2015 in Burkina Faso that CFR was 8\%. WHO (2016a) found between 1995 and 2014 in meningitis belt countries CFR $=10 \%$ [15]. Conversely, Collard et al. found in Niger an increase of CFR from $6.7 \%$ in 2008 to $12.2 \%$ in 2011 [9]. Concerning meningitis deaths, this study found that in Niger there was no significant difference of fatal meningitis before and after the introduction of MACV (IRR $0.61,95 \%$ CI $0.21-1.77, \mathrm{p}=0.188$ ) probably because of the high number of meningitis deaths during meningitis epidemics from 2015 to 2017. Novak et al. found in Burkina Faso 1 year after the introduction of MACV a $64 \%$ decline in risk of fatal meningitis [11]. However, this study found that 7 years after the introduction of MACV, there was a significant difference of reduction of fatal meningitis (IRR 0.38 , 95\% CI 0.13 1.77).

\subsection{Bacterial Meningitis Pathogens After MACV Introduction}

The study found the decline of $N$. meningitidis A after 2010 with the introduction of MACV and the predominance of other meningitis pathogens ( $N$. meningitidis W135, $N$. meningitidis $\mathrm{C}, N$. meningitidis $\mathrm{X}$, and Streptococcus pneumoniae) with the near disappearance of $N$. meningitidis A cases and epidemics in African meningitis belt countries $[18,21,24-28]$. The results of the study confirmed those found in the literature.

\subsection{Limitations of the Study}

For a few countries, there were missing data. Fortunately, the missing data from countries were not significant at slightly under $2.5 \%$. The generalizability of this study is feasible due to the large sample size from the 21 countries chosen for this study out of 26 countries of the African meningitis belt.

\section{Conclusions}

Bacterial meningitis infection remains a burden in the African meningitis belt countries. The study showed the effectiveness of introduction of MACV in African meningitis belt. The key findings of the study indicated that meningitis disease is reducing since the introduction of MACV, meningitis deaths as well. The high CFR $10 \%$ and over with $46 \%$ decline after the introduction of MACV that can be explained by the improvement of interventions against meningitis disease and the change of treatment protocol with ceftriaxone that is used since 2014. The cases of $N$. meningitidis A in African meningitis belt countries that vaccinated have declined significantly following the extensive roll-out of MACV. The findings showed that $N$. meningitidis A is being eliminated. Even though the cases significantly decreased, it still a threat, and the bacterial profile changed with the predominance of $N$. meningitidis $(\mathrm{C}$, $\mathrm{W} 135, \mathrm{X}, \mathrm{Y}$ ) and S. pneumoniae.

The vaccination coverage obtained during campaigns were high and contributed to reducing $N$. meningitidis A cases. The study demonstrated that high MACV coverage and enhanced surveillance are pivotal to reduce the meningitis burden. Results can be used to inform policy and public health practice to reduce the meningitis cases and improve quality of live in the community.

\section{Disclaimer}

The findings and conclusions in this report are those of the author and do not necessarily represent the official position of the Walden University.

\section{Competing Interest}

The authors declare that they have no competing interests. 


\section{Ethical Procedures}

Two databases from WHO Inter-country Support Team of WEST Africa (IST WA) websites were used. The request for the use of secondary data from these databases was done in December 2016 to the regional director of WHO in Africa, and the approval was given on December 19, 2017. The secondary data used for this study both are anonymous, confidential, and will be secured hard and soft copies (password for folders). Walden University gave IRB approval on February 7, 2018 (02-07-18-0409702). There was no conflict of interest and, no incentive was taken for this study.

\section{Appendix}

Data use Agreement

\section{DATA USE AGREEMENT}

This Data Use Agreement ("Agreement"), effective as of December 19.2017 is entered into by and between ANDRE ARSENE BITA FOUDA. "Data Recipient" and WORLD HEALTH ORGANIZATION "Data Provider". The purpose of this Agreement is to provide Data Recipient with access to a Limited Data Set ("LDS") for use in research in accord with the HIPAA and FERPA Regulations.

1. Definitions. Unless otherwise specified in this Agreement, all capitalized terms used in this Agreement not othenwise defined have the meaning established for purposes of the "HIPAA Regulations" codified at Title 45 parts 160 through 164 of the United States Code of Federal Regulations, as amended from time to time.

2. Preparation of the LDS, Data Provider shall prepare and furnish to Data Recipient a LDS in accord with any applicable HIPAA or FERPA Regulations

Data Fields in the LDS. No direct identifiers such as names may be included in the Limited Data Set (LDS). The researcher will also not name the organization in the doctoral project report that is published in Proquest. In preparing the LDS, Data Provider or designee shall include the data fields specified as follows, which are the minimum necessary to accomplish the research:

- Meningitis disease data in Africa January 2004 - December 2017

- Incidence (suspected cases, epidemics)

- Deaths

- Crude fatality rate

- Alert and epidemic thresholds

- Case confirmation from laboratories

- Meningitis bacterial profile

- Epidemic investigation reports

- Meningitis control program reports

- MenAfriVac introduction in countries of meningitis belt January 2010-

December 2017

- Coverage (administrative and surveys: all levels: national, regional. peripheral)

- Information on preparation, implementation, monitoring and evaluation

- Adverse events following immunization and case management

Responsibilities of Data Recipient. Data Recipient agrees to:

a. Use or disclose the LDS only as permitted by this Agreement or as required by law;

b. Use appropriate safeguards to prevent use or discksure of the LDS other than as permitted by this Agreement or required by law;

c. Report to Data Provider any use or disclosure of the LDS of which it becomes aware that is not pennitted by this Agreement or required by law; 
d. Require any of its subcontractors or agents that receive or have access to the LDS to agree to the same restrictions and conditions on the use and/or disclosure of the LDS that apply to Data Recipient under this Agreement; and

e. Not use the information in the LDS to identify or contact the individuals who are data subjects.

3. Permitted Uses and Disclosures of the LDS. Data Recipient may use and/or disclose the LDS for its research activities only.

4. Term and Termination.

a. Term. The term of this Agreement shall commence as of the Effective Date and shall continue for so long as Data Recipient retains the LDS, unless sooner terminated as set forth in this Agreement.

b. Termination by Data Recinient. Data Recipient may terminate this agreement at any time by notifying the Data Provider and returning or destroying the LDS.

c. Termination by Data Provider. Data Provider may terminate this agreement at any time by providing thirty (30) days prior written notice to Data Recipient.

d. For Breach. Data Provider shall provide written notice to Data Recipient within ten (10) days of any determination that Data Recipient has breached a material term of this Agreement. Data Provider shall afford Data Recipient an opportunity to cure said alleged material breach upon mutually agreeable terms. Failure to agree on mutually agreeable terms for cure within thirty (30) days shall be grounds for the immediate termination of this Agreement by Data Provider.

e. Effect of Termination. Sections 1, 4, 5, 6(e) and 7 of this Agreement shall survive any termination of this Agreement under subsections $\mathrm{c}$ or d.

5. Miscellaneous.

a. Change in Law. The parties agree to negotiate in good faith to amend this Agreement to comport with changes in federal law that materially alter either or both parties' obligations under this Agreement. Provided however, that if the parties are unable to agree to mutually acceptable amendment(s) by the compliance date of the change in applicable law or regulations, either Party may terminate this Agreement as provided in section 6.

b. Construction of Terms. The terms of this Agreement shall be construed to give effect to applicable federal interpretative guidance regarding the HIPAA Regulations. 
c. Ne Third Party Bencticiarics, Nothing in this Agreement shall confer upon any person other than the parties and their respective successors or assigns, any rights, remedies, obligations, or liabilities whatsoever.

d. Scunterparts. This Agreement may be executed in one or more counterparts, each of which shall be deemed an original, but all of which together shall comstitute one and the same instrument.

e. Headings The headings and other captions in this Agreement are for convenience and reference only and shall not be used in interpreting, construing or enforcing any of the provisions of this Agreement.

IN WITNESS WHEREOF, each of the undersigned has caused this Agreement to be duly executed in its name and on its behalf.

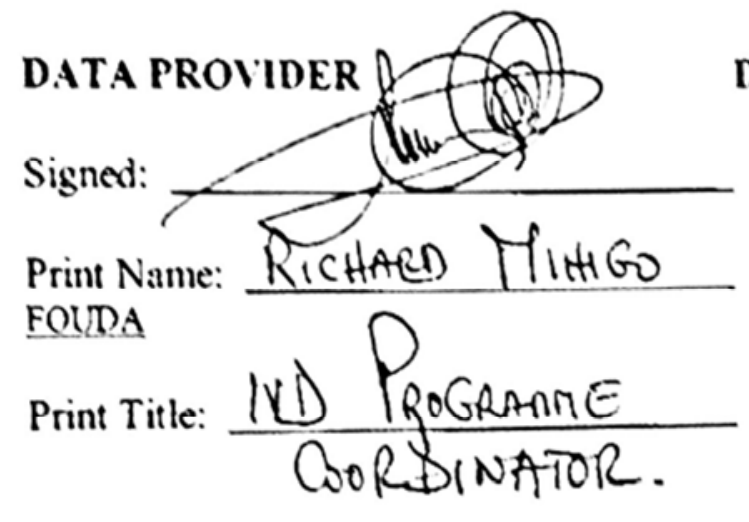

\section{Acknowledgements}

The author would like to thank my spouse Dr Gertrude Bita; Dr. German A. Gonzalez. and Dr. Namgyal L. Kyulo from Walden University; the Dean of the Faculty of Health and Pharmaceutical Sciences of Douala Prof. Albert Mouelle Sone; the Regional Director of WHO AFRO Dr. Matshidiso Moeti, the FRH/AFRO Director Dr. Felicitas ZAWAIRA, the IVE/WHO AFRO Coordinator Dr. Richard Mihigo; the WHO Representative of Madagascar Dr. Charlotte Faty Ndiaye; Dr. Marie-Pierre Presiozi WHO Geneva; Dr. Banche Anya and Dr Carol Tevi Benissan in WHO AFRO; Dr Ado Bwaka; Dr Amadou Fall; and Mr. Clement Lingani from WHO ISTWA; and Mr. Claude Bika. Their relevant guidance, advice and support are highly appreciated.

\section{References}

[1] World Health Organization. Meningococcal meningitis, https://www.who.int/en/news-room/factsheets/detail/meningococcal-meningitis; 2018 [assessed 23 March 2019].

[2] Centers for Disease Control and Prevention. An update on global partners reaching the ultimate goal of eliminating epidemic meningitis as a public health concern in Africa,

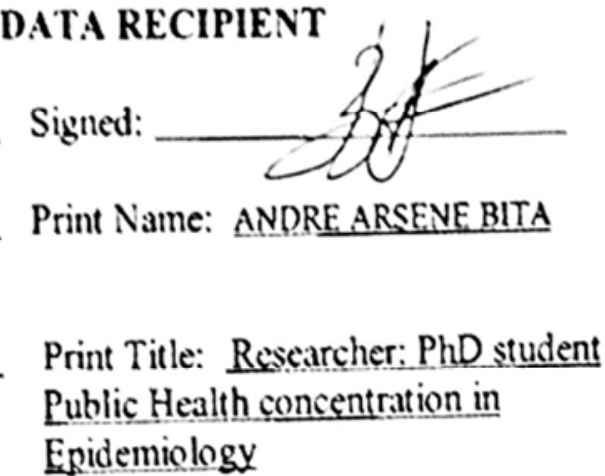

http://www.cdc.gov/globalhealth/stories/meningitis.htm; 2015 [Accessed 1 May 2019].

[3] Greenwood B. Meningococcal meningitis in Africa. Transactions of the Royal Society of Tropical Medicine and Hygiene 1999; 93 (4), 341-353. https://doi:10.1016/S00359203 (99) 90106-2.

[4] Lapeyssonnie L. Cerebrospinal meningitis in Africa (in French), https://apps.who.int/iris/bitstream/handle/10665/72037/bulleti n_supp\%20_Vol28.pdf? sequence=1\&isAllowed=y; 1963 [accessed 5 May 2019].

[5] Harrison LH, Trotter CL, Ramsay ME. Global epidemiology of meningococcal disease. Vaccine 2009); 27 (S2), B51-63. https://doi:10.1016/j.vaccine.2009.04.063.

[6] Stephens DS, Greenwood B, Brandzaeg P. Epidemic meningitis, meningococcaemia, and Neisseria meningitidis. Lancet 2007; $369 \quad$ (9580), 2196-2210. https://doi:10.1016/S0140-6736 (07) 61016-2.

[7] World Health Organization. Global Health Observatory (GHO) data: Meningococcal meningitis, http://www.who.int/gho/epidemic_diseases/meningitis/en/201 9; [accessed 5 May 2019].

[8] Centers for Disease Control and Prevention. Working to eliminate epidemic meningitis in Sub-Saharan Africa, http://www.cdc.gov/ncird/div/DBD/newsletters/2012/summer/ mening.html; 2012 [accessed 4 May 2019]. 
[9] Collard JM., Issaka B, Zaneidou M, Hugonnet S, Nicolas P, Taha MK et al. Epidemiological changes in meningococcal meningitis in Niger from 2008 to 2011 and the impact of vaccination. BioMed Central Infectious Diseases 2013. 13, 576. https://doi:10.1186/1471-2334-13-576.

[10] Djingarey MH, Barry R, Bonkoungou M, Tiendrebeogo S, Sebgo R, Kandolo D, et al. Effectively introducing a new meningococcal A conjugate vaccine in Africa: The Burkina Faso experience. Vaccine 2012; 30 (S2): B40-45. https://doi:10.1016/j.vaccine.2011.12.073.

[11] Novak RT, Kambou JL, Diomandé FVK, Tarbangdo TF, Ouédraogo-Traoré R, Sangaré L, et al. Serogroup A meningococcal conjugate vaccination in Burkina Faso: analysis of national surveillance data. Lancet Infectious Diseases 2012; 12, 757-764. https://doi:10.1016/s1473-3099 (12) 70168-8.

[12] Daugla DM, Gami JP, Gamougam K, Naibei N, Mbainadji L, Narbé M, et al. Effect of a serogroup A meningococcal conjugate vaccine (PsA-TT) on serogroup A meningococcal meningitis and carriage in Chad: A community study. Lancet 2013; 383 (9911), 40-47. https://doi:10.1016/S0140-6736 (13) 61612-8.

[13] Trotter CL, Lingani C, Katya F, Cooper LV, Bita A, TeviBenissan $C$, et al. The impact of MenAfriVac $\mathbb{R}$ in nine countries of the African meningitis belt, 2010-2015: An analysis of surveillance data. Lancet Infectious Disease 2017; 17, (S1473-3099) 30301-30308. https://doi:10.1016/S14733099 (17) 30301-8.

[14] Kristiansen PA, Diomandé F, Ky BA, Sanou I, Ouédraogo AS., Ouédraogo R, et al. Impact of the Serogroup A

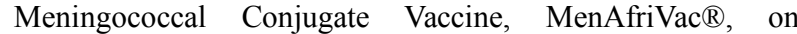
Carriage and Herd Immunity. Clinical Infectious Diseases 2013; 56 (3), 354-363. doi:10.1093/cid/cis892.

[15] Diallo AO, Soeters HE, Medah I, Ouédraogo-Traoré R, Sangaré L, Bicaba B, et al. Evaluation of meningococcal serogroup A conjugate vaccine impact on meningitis epidemics in Burkina Faso: A five-year (2011-2015) followup analysis. PLoS One 2017; 12 (11), e0187466. https://doi:10.1371/journal.pone.0187466.

[16] Diomandé FV, Djingarey MH, Daugla DM, Novak RT, Kristiansen PA, Collard JM, et al. Public health impact after the introduction of PsA-TT: The first 4 years. Clinical Infectious Diseases 2015; 61 (S5), S467-472. https://doi:10.1093/cid/civ499.

[17] LaForce FM, Djingarey M, Viviani S, Preziosi MP. Successful African introduction of a new Group A meningococcal conjugate vaccine: Future challenges and next steps. Vaccines \& Immunotherapeutics 2017; 14 (5), 1098-1102. https://doi:10.1080/21645515.2017.1378841.

[18] Lingani C, Bergeron-Caron C, Stuart JM, Fernandez K, Djingarey $\mathrm{MH}$, Ronveaux $\mathrm{O}$, et al. Meningococcal meningitis surveillance in the African meningitis belt, 2004-2013. Clinical Infectious Diseases 2015; 61 (S5), S410-415. https://doi:10.1093/cid/civ597.
[19] Sambo L, Chan M, Davis S, Lake A, Berkley CP, Elias CJ. A vaccine meets its promise: success in controlling epidemic meningitis in Sub-Saharan Africa. Clinical Infectious Diseases 2015; 61 (S5), S387-388. https://doi:10.1093/cid/civ490.

[20] Stuart JM. Impact of serogroup A meningococcal conjugate vaccine for Africa. Human Vaccines \& Immunotherapeutics 2018; $14 \quad$ (5), 1116-1117. https://doi:10.1080/21645515.2017.1412022.

[21] Fall A, Fouda Bita A, Lingani C, Djingarey M, Tevi-Benissan C, Preziosi MP, et al. Elimination of Epidemic Meningitis in the African Region: Progress and Challenges: 2010-2016. J Immunol Sci 2018; S (006): 41-45.

[22] LaForce FM, Okwo-Bele JM. Eliminating Epidemic Group A meningococcal meningitis in Africa through a new vaccine. Health Affairs 2011; 30 (6), 1049-1057. https://doi:10.1377/hlthaff.2011.0328.

[23] Mueller JE. Conjugate vaccine introduction in the African meningitis belt: meeting surveillance objectives. Tropical Medicine \& International Health 2013; 18 (1), 58-64. https://doi:10.1111/tmi.12009.

[24] Carod AFJ. Meningococcal meningitis: vaccination outbreak response and epidemiological changes in the African meningitis belt. International Health 2015; 7 (4): 226-227. https://doi:10.1093/inthealth/ihv025.

[25] Obaro SK, Habib AG. Control of meningitis outbreaks in the African meningitis belt. Lancet Infectious Diseases 2016; 16 (4), 400-402. https://doi:10.1016/S1473-3099 (16) 00121-3.

[26] Funk A Uadiale K Kamau C Caugant DA Ango U Greig J. Sequential outbreaks due to a new strain of Neisseria meningitidis serogroup $C$ in northern Nigeria, 2013-14. PLoS Curr. 2014; (published online December 29) 10.1371/currents.outbreaks.b50c2aaf1032b3ccade0fca0b63ee 518.

[27] Delrieu I Yaro S Tamekloe TA et al. Emergence of epidemic Neisseria meningitidis serogroup $\mathrm{X}$ meningitis in Togo and Burkina Faso. PLoS One. 2011; 6: e19513.

[28] Sidikou F Zaneidou M Alkassoum I et al. Emergence of epidemic Neisseria meningitidis serogroup C in Niger, 2015: an analysis of national surveillance data. Lancet Infect Dis. 2016; 16: 1288-1294.

[29] Standard operating procedures for enhanced meningitis surveillance in Africa, https://apps.who.int/iris/bitstream/handle/10665/312141/9789 290234241-eng.pdf; 2019 [accessed 5 May 2019].

[30] Cibrelus L, Lingani C, Fernandez K, Perea WA, Hugonnet S. Risk assessment and meningococcal A conjugate vaccine Introduction in Africa: The district prioritization tool. Clinical Infectious Diseases 2015; $61 \quad$ (S5), S442-450. https://doi:10.1093/cid/civ671. 